\title{
Zinc Status of Infants with Fetal Alcohol Syndrome
}

\author{
FARAHNAK K. ASSADI AND MOHSEN ZIAI \\ University of Illinois Health Sciences Center, Chicago, Illinois 60612 [F.K.A.] and Georgetown University School \\ of Medicine, Washington, D.C. [M.Z.]
}

\begin{abstract}
Plasma and urinary zinc levels were examined in 6 infants with fetal alcohol syndrome to determine whether zinc deficiency, if present in fetal alcohol syndrome patients, is secondary to an increased urinary zinc excretion. Six infants born to nonalcoholic mothers served as controls. There was no significant difference in creatinine clearance, urine flow rate, or plasma albumin concentrations between the two groups. Plasma concentrations of zinc were significantly lower in fetal alcohol syndrome patients $(62.5 \pm 2.8 \mu \mathrm{g} / \mathrm{dl})$ in comparison to controls $(71$ $\pm 1.8 \mu \mathrm{g} / \mathrm{dl}),(p=0.0001)$. Urinary excretion of zinc in fetal alcohol syndrome patients averaged $646 \pm 125 \mu \mathrm{g} / 24$ $h$, significantly higher than in control subjects $(76.6 \pm 22$ $\mu \mathrm{g} / 24 \mathrm{~h}),(p=0.0001)$. Thus (1) lower plasma zinc levels are present in infants with fetal alcohol syndrome and (2) increased urinary zinc excretion appears to be responsible for decreased plasma zinc concentrations. (Pediatr Res 20: 551-554, 1986)
\end{abstract}

\section{Abbreviations}

FAS, fetal alcohol syndrome

PZn, plasma zinc concentration

The teratogenicity of alcohol has been demonstrated in humans through clinical and epidemiological studies and in animals through controlled laboratory experiments (1). The effects on offspring range from decreased birth weight and functional deficits at lower levels of alcohol intake to FAS and early or late fetal death at higher doses $(2,3)$. The principal features of FAS include prenatal and postnatal growth retardation, facial dysmorphic features, and central nervous system involvement $(4,5)$. The mediation of these effects through the nutritional status of the mother with respect to zinc has been hypothesized (6). Hyperzincuria and tendency toward lower PZn concentrations have been reported in alcoholic patients $(7,8)$. Studies of zinc deficiency in human pregnancy have also shown a strong positive correlation with fetal dysmorphogenesis (9) in a manner similar to those reported in rat pups when the dams were restricted in zinc intake during gestation (10).

In view of the fact that excessive alcohol intake may deplete body stores of zinc and since zinc plays a vital role in DNA synthesis and cell division $(11,12)$, one may hypothesize that a relative zinc deficiency during gestation may be one of the mechanisms underlying alcohol-induced fetal dysmorphogenesis.

The present study was designed to evaluate zinc status in

Received September 25, 1985; accepted February 4, 1986

Correspondence, Farahnak K. Assadi, M.D., Departments of Pediatrics, University of Illinois Health Sciences Center, 840 South Wood Street, Chicago, IL 60612 infants with FAS and to determine whether zinc deficiency, if present in the FAS, is secondary to an increased urinary zinc excretion.

\section{PATIENTS AND METHODS}

Six alcoholic mothers and their offspring (age 6 to 12 months) were selected from a large group of inmates incarcerated at a Tehran Prostitutional Center in 1978. The mothers were spree drinkers and had had a history of alcoholism from 5 to $8 \mathrm{yr}$. None was addicted to any other drugs. All satisfied the criteria for alcoholism as defined by the criteria committee of the $\mathrm{Na}$ tional Council of Alcoholism (13). The six selected infants of these women were recognized as having the pattern of altered growth and morphogenesis characteristic of the FAS $(4,5)$ (Table 1). All presented in early infancy with symptoms including poor feeding, vomiting, polyuria, dehydration, and failure to thrive. None had malabsorption syndromes, glucosuria, aminoaciduria, proteinuria, hyperphosphaturia (defined as tubular reabsorption of phosphate $<85 \%$ ), or hypercalciuria (urine calcium/urine creatinine $>0.25)$. Normal blood concentrations of glucose $(91.5$ $\pm 5 \mathrm{mg} / \mathrm{dl})$, calcium $(8.1 \pm 0.3 \mathrm{mg} / \mathrm{dl})$, phosphate $(4.0 \pm 0.4$ $\mathrm{mg} / \mathrm{dl})$, alkaline phosphatase $(125 \pm 11 \mathrm{U} /$ liter $)$, total proteins $(6.8 \pm 1.1 \mathrm{~g} / \mathrm{dl})$, and albumin $(3.7 \pm 0.3 \mathrm{~g} / \mathrm{dl})$ were obtained in all patients. Liver function tests were normal with SGOT $32 \pm$ $4 \mathrm{U} /$ liter, SGPT $21 \pm 3 \mathrm{U} /$ liter, and total bilirubin $0.5 \pm 0.1$ $\mathrm{mg} / \mathrm{dl}$. Tuberculin skin tests were negative and sweat tests were normal. Six infants born to nonalcoholic mothers with postnatal ages of 4 to 10 months (mean 6.9 months) and weights of 5.0 to $9.8 \mathrm{~kg}$ (mean $7.38 \mathrm{~kg}$ ) served as controls. Although the control infants were younger than the FAS infants, group mean values for weight and height were not significantly different. Other characteristics of both the FAS and control infants have been reported previously (27). Dietary zinc intake by the FAS patients and the normal control infants appeared to be similar. All were fed cow's milk formula after birth. Solid foods were introduced by the end of the 4th month of life in the form of cereals, fruit juice, and pudding providing a caloric intake of 105 (range 100110) $\mathrm{kcal} / \mathrm{kg} /$ day. This diet contained 3 to $5 \mathrm{mg}$ zinc by calculation. Strained cooked vegetables and meats were added into the diet by the end of the 6th month. Twenty-four-h specimens of urine were collected by means of bladder catheterization directly into sterilized and acidified plastic containers and immediately frozen for later analysis. At the midpoint of each urine collection $3 \mathrm{ml}$ venous blood samples were drawn into acidcleaned sterile plastic syringes through stainless-steel needles and immediately placed in plastic tubes containing heparin. Plasma was separated from erythrocytes within $1 \mathrm{~h}$ and then returned to plastic tubes. Urine and plasma specimens were frozen promptly at $-20^{\circ} \mathrm{C}$ and analyzed later for creatinine (Beckman autoanalyzer methods) and zinc (atomic absorption spectrophotometry) (14). All specimens were analyzed fresh or within 24-h of storage. The intraassay coefficient of variation of the method for plasma 
Table 1. Clinical features observed in infants with $F A S$

\begin{tabular}{|c|c|c|c|c|c|c|}
\hline \multirow[b]{2}{*}{ Feature } & \multicolumn{6}{|c|}{ Patient } \\
\hline & 1 & 2 & 3 & 4 & 5 & 6 \\
\hline Age $(\mathrm{mo}) / \mathrm{sex}$ & $12 / \mathrm{F}$ & $10 / \mathrm{F}$ & $10 / \mathrm{M}$ & $8 / F$ & $7 / \mathrm{F}$ & $6 / \mathrm{M}$ \\
\hline \multicolumn{7}{|l|}{$\begin{array}{l}\text { Growth deficiency ( } \leqslant 10 \text { th } \\
\text { percentile) }\end{array}$} \\
\hline Prenatal & + & + & + & + & + & + \\
\hline Postnatal & + & + & + & + & + & + \\
\hline \multicolumn{7}{|l|}{ Facial characteristics } \\
\hline Short palpebral fissures & + & + & + & + & + & + \\
\hline Hypoplastic philtrum & + & + & - & + & + & + \\
\hline Hypoplastic maxilla & + & + & + & + & - & - \\
\hline $\begin{array}{l}\text { Microcephaly }(\leqslant 3 \text { rd per- } \\
\text { centile) }\end{array}$ & + & - & + & + & + & + \\
\hline \multicolumn{7}{|l|}{ Central nervous system } \\
\hline Developmental delay & + & + & + & + & + & + \\
\hline Hypotonia & - & - & + & - & + & - \\
\hline \multicolumn{7}{|l|}{ Skeletal } \\
\hline Joint anomalies* & - & - & - & + & - & - \\
\hline $\begin{array}{l}\text { Altered plamar crease pat- } \\
\text { tern }\end{array}$ & - & + & - & - & - & - \\
\hline Cardiac anomaly $\dagger$ & - & - & - & - & + & - \\
\hline
\end{tabular}

* Syndactyly of the second and third toes bilaterally and limitation of motion at elbows.

$\dagger$ Atrial septal defect; +, present; -, absent.

zinc was 0.011 and of the method for urine, 0.013 . The corresponding interassay coefficients of variation were 0.019 and 0.03 , respectively. Recovery of zinc determined by the method was $98 \%$.

Creatinine clearance was estimated as urinary creatinine concentration $\times$ urinary flow rate/plasma creatinine concentration.

The protocol for this study was approved by the Institutional Review Board, The University of Medical Sciences of Iran. Informed written maternal consent was obtained for all patients prior to study. Statistical analysis of the results was done using the Student's $t$ test for unpaired variables. Data are presented as the mean $\pm \mathrm{SD}$.

\section{RESULTS}

The results of the PZn determinations in FAS patients are presented and compared to the data in normal subjects (Fig. 1). The mean PZn in the FAS patients was $62.5 \pm 2.8 \mu \mathrm{g} / \mathrm{dl}$. In normal infants, the mean value was $71 \pm 1.8 \mu \mathrm{g} / \mathrm{dl}(p=0.0001)$. PZn levels in all FAS patients were lower than in all control subjects. No FAS patient had a value greater than $65 \mu \mathrm{g} / \mathrm{dl}$.

Total urinary excretion of zinc is shown in Figure 2. The mean excretion in the patient group, $646 \pm 125 \mu \mathrm{g} / 24 \mathrm{~h}$, was significantly higher than that for the normal group, $76.6 \pm 22 \mu \mathrm{g} / 24 \mathrm{~h}$ $(p=0.0001)$. Only one of the six normal infants had values greater than $100 \mu \mathrm{g} / 24 \mathrm{~h}$. In contrast, zinc excretion of $391 \mu \mathrm{g} /$ $24 \mathrm{~h}$ or greater was found in all patients with FAS. Five of the six patients with FAS had values greater than $680 \mu \mathrm{g} / 24 \mathrm{~h}$. There was no significant difference in creatinine clearance or urinary flow rate between the two groups (Table 2).

\section{DISCUSSION}

The present study suggests that infants exposed to intrauterine alcohol have lower plasma $\mathrm{Zn}$ levels and increased urinary $\mathrm{Zn}$ excretion as compared to control infants when examined 6 to 12 months after birth.

Decreased PZn levels can result from inadequate dietary intake $(15,16)$, impaired absorption (17), excessive urinary excretion $(7,8,18)$, and inherited defects in zinc metabolism such as occurs in acrodermatitis enteropathica (19). Inadequate dietary zinc intake cannot account for the lowered PZn levels observed in

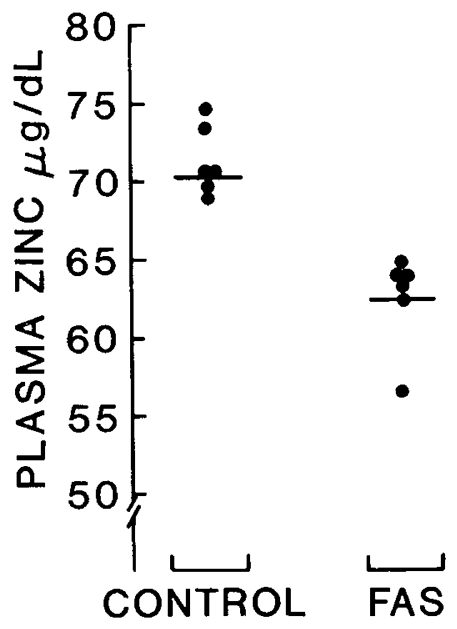

Fig. 1. Plasma zinc concentrations are compared in FAS infants and normal controls. Mean values are given by the horizontal lines.

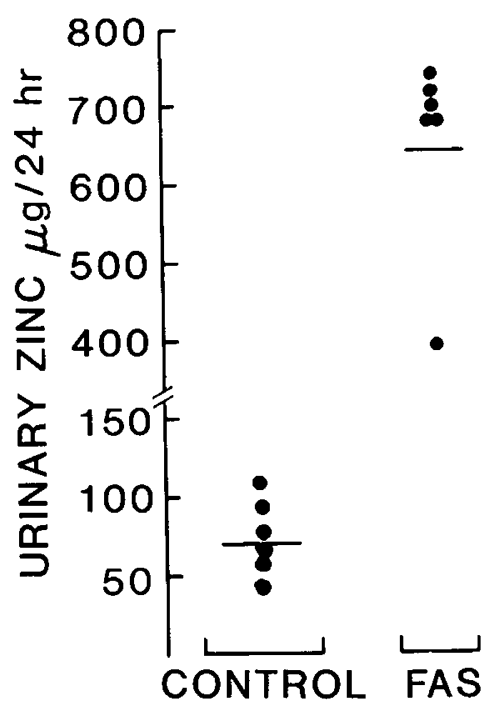

Fig. 2. Twenty-four-h urinary zinc excretion is compared in FAS infants and normal controls. Mean values are given by the horizontal lines.

our FAS patients since PZn deficiency did not occur in any of the six control subjects with comparable dietary intake. PZn levels are known to be dependent on plasma protein concentration since approximately 80 to $90 \%$ of zinc is bound to protein, mainly albumin (20). In this regard, plasma protein concentrations in FAS patients $(6.8 \pm 1.1 \mathrm{~g} / \mathrm{dl})$ were similar to those of controls $(7.1 \pm 1.4 \mathrm{~g} / \mathrm{dl})(p=\mathrm{NS})$. There was no evidence to suggest that any of the FAS patients had chronic diarrhea, malabsorption syndrome, or liver disease. Thus none of the usual disturbances in zinc absorption or metabolism was suspected in our patients.

The finding of marked hyperzincuria in virtually every FAS patient suggests that the increased urinary excretion of zinc may be the cause for the low PZn values. Each patient with FAS had a markedly increased urinary zinc excretion at the time of hypozincemia (Table 2). The mechanisms and factors determining the renal excretion of zinc are largely unknown. The albuminbound zinc is in equilibrium with small molecular weight amino acids, primarily histidine and to a lesser extent cysteine (21). Since histidine-zinc ligands are of relatively small molecular weight, they cross the renal glomerulus and are readily excreted in the urine (21). Approximately $0.5 \mathrm{mg}$ of zinc is excreted each 
Table 2. Summary of data obtained in six infants with $F A S^{*}$

\begin{tabular}{|c|c|c|c|c|c|}
\hline Patient & Wt (kg) & $\mathrm{C}_{\mathrm{cr}}(\mathrm{ml} / \mathrm{min})$ & $\mathrm{PZn}(\mu \mathrm{g} / \mathrm{dl})$ & $\mathrm{V}$ (ml/day) & $\mathrm{UZn} \cdot \mathrm{V}(\mu \mathrm{g} /$ day $)$ \\
\hline 1 & 9.1 & 65 & 57 & 374 & 715 \\
\hline 2 & 8.3 & 60 & 64 & 302 & 696 \\
\hline 3 & 8.2 & 63 & 65 & 331 & 686 \\
\hline 4 & 7.4 & 58 & 62 & 302 & 391 \\
\hline 5 & 5.9 & 51 & 65 & 273 & 684 \\
\hline 6 & 5.3 & 47 & 63 & 316 & 704 \\
\hline $\begin{array}{l}\text { Mean } \pm \mathrm{SD} \\
\text { Controls } \\
\quad(n=6)\end{array}$ & $7.2 \pm 1.6$ & $57 \pm 7$ & $62.5 \pm 2.8 \dagger$ & $316 \pm 34$ & $646 \pm 125 \dagger$ \\
\hline Mean \pm SD & $7.4 \pm 1.5$ & $60 \pm 9$ & $71 \pm 1.8$ & $331 \pm 29$ & $77 \pm 22$ \\
\hline
\end{tabular}

${ }^{*} \mathrm{C}_{\mathrm{cr}}$, creatinine clearance; $\mathrm{V}$, urine flow rate; $\mathrm{UZn} \cdot \mathrm{V}$, urinary zinc excretion.

$\dagger p=0.0001$

day in the urine of adults and a similar quanity is excreted in the sweat (21).

The alterations in renal physiology responsible for the increased zinc excretion in FAS patients are also obscure. Previous studies have shown that the congenital malformations that result from severe prenatal zinc deficiency are probably caused by a defect in DNA and protein synthesis $(11,22)$. In addition, several investigators have shown that zinc deficiency lowers the activity of alcohol dehydrogenase in the intestine, liver, kidneys, testes, and bones of rats in comparison to their pair-fed controls (11, 23). Reduced activity of alcohol dehydrogenase, a zinc metalloenzyme, has been reported in alcoholic patient (24). The participation of zinc in the dehydrogenation of ethanol (25) and glutamic acid (26), two substrates that are clearly implicated in the metabolic changes seen in alcoholic patients, supports this view (21). Although not proven, it seems possible that the observed hyperzincuria in FAS infants may be related to the enzyme inhibition.

It is also possible that the increased urinary zinc excretion is a result of impaired renal tubular function induced by intrauterine alcohol exposure. Additional support for this hypothesis was provided more recently in studies of renal acidification in FAS infants (27). These data show that infants with FAS have a defect in distal acidification and potassium excretion which cannot be attributed to abnormal aldosterone secretion. The high urinary excretion of zinc, whatever the cause, could deplete zinc stores of the body in FAS patients so that inadequate amounts of zinc would be available for cellular functions.

In a study of maternal zinc deficiency in the rat, Hurley (10) reported a high incidence of congenital malformations in the affected offspring. Subsequently Flynn et al. (9) examined the relationship between zinc status and FAS in a cohort of pregnant women and reported that alcoholic pregnant women have significantly lower zinc levels than comparable nonalcoholic pregnant women and that the low plasma zinc values were associated with an increased rate of fetal dysmorphogenesis. Furthermore studies on animal models of the FAS have demonstrated that the combination of zinc deficiency and alcohol consumption has more severe effects on the fetus than either alcohol or zinc deficiency alone $(11,12)$. In a more recent study Keppen et al. (28) examined the effects of alcohol on progeny of pregnant mice fed a zinc-deficient diet compared to those fed a diet with adequate zinc. The results of their findings are in accord with previous reports $(11,12)$, indicating that the teratogenic effects of alcohol and low dietary zinc in combination are much greater than the effects of either alone.

The findings in the present study that FAS infants, as did their mothers during gestation (9), have low plasma zinc levels suggest the possibility of preventing fetal dysmorphogenesis by supplementing alcoholic pregnant women with zinc. Additional support for this hypothesis has been provided in a recent study reported by Jameson (29). In this study 312 Swedish pregnant women were enrolled. The 64 women with low plasma zinc levels at 14-wk gestation who were then given zinc supplement (45 mg elemental zinc daily) had a higher percentage of normal deliveries and normal infants than the 69 women with low plasma zinc who were not supplemented (63 versus $22 \%$ ), indicating that improvement of zinc nutriture during pregnancy can reduce the prevalence of birth defects. In this study none of the pregnant women was reported to be alcoholic. In an animal study of FAS, Keppen et al. (28) showed that fewer congenital malformations occurred in mice given the recommended amount of zinc compared to those given very low dietary zinc.

The ultimate question of the role of zinc in human FAS will require the demonstration that improvement of zinc nutriture in alcoholic women during pregnancy reduces the incidence or severity of birth defects in the offspring as compared to an untreated group. Further studies of zinc metabolism in alcoholic women and their neonates would seem justified.

Acknowledgments. The authors are especially grateful to the nursing staff of the Clinical Research Center, University of Medical Sciences of Iran whose efforts and understanding made possible the accumulation of much of these data. We also thank Ms. Gerald Gardner for her secretarial help.

\section{REFERENCES}

1. Streissguth AP, Landesman-Dwyer Martin JC, Smith DW 1980 Teratogenic effects of alcohol in humans and laboratory animals. Science 209:353-361

2. Clarren SK, Smith DW 1978 The fetal alcohol syndrome. N Engl J Med 298:1063-1067

3. Hanson JW, Streissguth AP, Smith DW 1978 The effects of moderate alcohol consumption during pregnancy on fetal growth and morphogenesis. J Pediatr 92:457-460

4. Jones KL, Smith DW 1973 Recognition of the fetal alcohol syndrome in early infancy. Lancet 1973;2:999-1001

5. Hanson JW, Jones KL, Smith DW 1976 Fetal alcohol syndrome, experience with 41 patients. JAMA 235:1458-1460

6. Jameson S 1976 Effects of zinc deficiency in human production. Acta Med Scand 593(suppl): $1-89$

7. Sullivan JF, Lankford HG 1962 Urinary excretion of zinc in alcoholism and postalcoholic cirrhosis. Am J Clin Nutr 10:153-157

8. Helwig HL, Hoffer EM, Thielen WC, Alcocer AE, Hotelling DR, Rogers WH, Lendch J 1966 Urinary and serum zinc levels in chronic alcoholism. Am J Clin Pathol 45:156-159

9. Flynn A, Martier SS, Sokol RJ, Miller SI, Golden NL, Del Villano BC 1981 Zinc status of pregnant alcoholic women: a determinant of fetal outcome. Lancet 1:572-575

10. Hurley LS 1969 Zinc deficiency in the developing rat. Am J Clin Nutr 22:13321339

11. Prasad AS, Oberleas D, Miller ER, Lueck RW 1971 Biochemical effect of zinc deficiency: changes in activities of zinc-dependent enzymes and ribonucleic acid and deoxyribonucleic acid content of tissues. J Lab Clin Med 77:144152

12. Chvapil M 1976 Effect of zinc on cells and biomembranes. Med Clin North Am 60:799-812

13. Criteria for the diagnosis of alcoholism 1972 Criteria Committee, National Council on Alcoholism. Ann Intern Med 77:249-258

14. Merets S, Henkin RI 1971 Simultaneous direct estimation by atomic absorption spectrophotometry of copper and zinc in serum, urine, and cerebrospinal fluid. Clin Chem 17:369-373

15. Shaw JCL 1979 Trace elements in the fetus and young infant 1. Zinc. Am $\mathbf{J}$ 
Dis Child 13:1260-1268

16. Gordon EF, Gordon RC, Passal DB 1981 Zinc metabolism: basic, clinical, and behavioral aspects. J Pediatr 99:341-349

17. McCane RA, Widdowson EM 1942 the absorption and excretion of zinc. Biochem J 36:692-696

18. Wester PO 1975 Zinc during diuretic treatment. Lancet 1:578

19. Moynahan EJ 1974 Acrodermatitis enteropathica: a lethal inherited human zinc-deficiency. Lancet 2:399-400

20. Prasad AS, Oberleas D 1970 Binding of zinc to amino acids and serum proteins in vitro. J Lab Clin Med 76:416-425

21. Prasad AS 1979 Clinical, biochemical, and pharmacological role of zinc. Ann Rev Pharmacol toxicol 20:393-426

22. Prasad AS, Oberleas D 1974 Thymidine Kinase activity and incorporation of thymidine into DNA in zinc deficient tissue J Lab Clin Med 83:634-639

23. Prasad AS, Oberleas D 1971 Changes in activity of zinc-deficient enzymes in
Zinc-deficient tissues of rats. J Appl Physiol 31:842-846

24. Vallee BL, Warren EC, Wacker MD, Bartholomay AF, Hoch FL 1957 Zinc metabolism in hepatic dysfunction II: correlation of metabolic patterns with biochemical findings. N Engl J Med 257:1055-1065

25. Vallee BL, Hoch FL $1955 \mathrm{Zinc}$, component of yeast alcohol dehydrogenase. Proc Natl Acad Sci USA 41:327-338

26. Vallee BL, Adelstein SL, Olson JA 1955 Glutamic dehydrogenase of beef liver, zinc metalloenzyme. J Am Chem Soc 77:5196

27. Assadi FK, Ziai M 1985 Impaired renal acidification in infants with fetal alcohol syndrome. Pediatr Res 19:850-853

28. Keppen LD, Pyshert T, Rennert OM 1985 Zinc deficiency acts as a co-teratogen with alcohol in fetal alcohol syndrome. Pediatr Res 19:944-947

29. Jameson S 1982 Zinc status and pregnancy outcome in humans. In: Prasad AS, Dreosti IE, Hetzel BS (eds) Clinical Applications of Recent Advances in Zinc Metabolism. Alan R. Liss Inc, New York, pp 39-52

\section{Announcements}

\section{European Society for Pediatric Research}

The European Society for Pediatric Research will hold its next meeting in Groningen, The Netherlands, September 7-10, 1986. The following working groups will join the meeting: Paediatric Allergy and Clinical Immunology; Paediatric Pharmacology; Perinatology; and Paediatric Microcirculation. The main topics will be Nutrition and Metabolism, Hepatic Metabolism, Fetal and Neonatal Metabolism, Developmental Neurology, Genetics, Immunology, Pharmacology, Microcirculation, and Oncology.

Travel bursaries are available for young investigators, particularly from Eastern Europe. For further information, contact $\mathbf{J}$. Fernandes, Department of Paediatrics, University Hospital, 59 Oostersingel, 9713 EZ Groningen, The Netherlands.

\section{Australia Hosts \\ 10th IUPHAR Congress}

The 10th International Congress of Pharmacology will be held in Sydney, Australia, August 23-28, 1987. The organizers are planning a scientific program which will identify the key areas in which there is rapid growth. The format will include invited lectures, symposia, free communications, poster sessions, symposia and workshops.

The Congress will make full use of Sydney's famous attractions and facilities such as the Sydney Opera House and the harbor.

For further information, contact the Secretariat: 10th IUPHAR, GPO Box 2609, Sydney NSW 2001, Australia. 